\title{
Cerebral aneurysm exclusion by CT angiography based on subarachnoid hemorrhage pattern: a retrospective study
}

\author{
Marc Kelliny ${ }^{1}$, Philippe Maeder ${ }^{1}$, Stefano Binaghi ${ }^{1}$, Marc Levivier ${ }^{2}$, Luca Regli ${ }^{3}$, Reto Meuli ${ }^{1 *}$
}

\begin{abstract}
Background: To identify patients with spontaneous subarachnoid hemorrhage for whom $C T$ angiography alone can exclude ruptured aneurysms.

Methods: An observational retrospective review was carried out of all consecutive patients with non-traumatic subarachnoid hemorrhage who underwent both CT angiography and catheter angiography to exclude an aneurysm. CT angiography negative cases (no aneurysm) were classified according to their $\mathrm{CT}$ hemorrhage pattern as "aneurismal", "perimesencephalic" or as "no-hemorrhage."
\end{abstract}

Results: Two hundred and forty-one patients were included. A CT angiography aneurysm detection sensitivity and specificity of $96.4 \%$ and $96.0 \%$ were observed. All 35 cases of perimesencephalic or no-hemorrhage out of 78 CT angiography negatives also had negative angiography findings.

Conclusions: $C T$ angiography is self-reliant to exclude ruptured aneurysms when either a perimesencephalic hemorrhage or no-hemorrhage pattern is identified on the $\mathrm{CT}$ within a week of symptom onset.

\section{Background}

Spontaneous subarachnoid hemorrhage (SAH) is a subtype of hemorrhagic stroke with an extremely poor prognosis. Eighty-five percent of non-traumatic SAHs are caused by ruptured intracranial aneurysms. Ten percent fit into the non-aneurismal perimesencephalic hemorrhage $(\mathrm{PMH})$ pattern, whose etiology remains debated. The final five percent are usually due to various rare causes, such as arteriovenous malformations [1].

When the CT is positive for subarachnoid blood, the combination of digital subtraction angiography (DSA) with 3D rotational angiography (3DRA) has been and is still considered the gold standard [2-6]. Meanwhile, CT angiography (CTA) has improved to a sensitivity of about $95 \%$ for detecting ruptured aneurysms, when compared to DSA [7-9]. Thus, in many centers, patients with SAH undergo CTA first which is often the basis for an endovascular or neurosurgical approach [10-12]. In any case, DSA remains a relatively riskier procedure

\footnotetext{
* Correspondence: reto.meuli@chuv.ch

'Department of Radiology, Centre Hospitalier Universitaire Vaudois and

University of Lausanne, 1011 Lausanne, Switzerland

Full list of author information is available at the end of the article
}

than CTA. In patients with coiled intracranial aneurysms, the complication rate of routine angiographic surveillance is $0.43 \%$ [13] and that of general diagnostic angiography in an academic center has a complication rate of $0.3 \%$ [14].

The sensitivity of the head CT for detecting SAH is usually around $95 \%$ the first day after SAH, then gradually drops to around $58 \%$ on the fifth day $[2,15-18]$. The sensitivity of the head CT diminishes with less significant hemorrhage. This decreased sensitivity with time is assumed to be due to the resorption of blood during the renewal of cerebrospinal fluid several times a day.

\section{Non-aneurismal perimesencephalic hemorrhage}

Non-aneurismal PMH has a good clinical outcome besides a low risk of re-bleeding and vasospasm. It comprises $96 \%$ of all PMHs [2,19-24]. The remaining $4 \%$ are due to vertebrobasilar aneurysms [23,25-27]. Non-aneurismal PMH is defined by a normal four-vessel high quality digital subtraction angiogram $[19,28,29]$ combined with the following distribution of blood in the subarachnoid space:
C Biomed Central

C 2011 Kelliny et al; licensee BioMed Central Ltd. This is an Open Access article distributed under the terms of the Creative Commons Attribution License (http://creativecommons.org/licenses/by/2.0), which permits unrestricted use, distribution, and reproduction in any medium, provided the original work is properly cited. 
1. The center of the hemorrhage is immediately anterior to the midbrain or the pons [19,29-31]. Variants of PMH occur in the basal cisterns around the midbrain: interpeduncular, crural, ambient, quadrigeminal, [19,29,32,33] prepontine and carotid cisterns [34].

2. Bleeding may extend up to the posterior part of the interhemispheric fissure and the basal part of the Sylvian fissure.

3. There is no intraparenchymal hematoma or frank intraventricular hemorrhage [19,29,32], although the presence of a small amount of sedimented blood in the occipital horns is acceptable.

Although non-aneurismal $\mathrm{PMH}$ and aneurismal hemorrhages may look alike on the $\mathrm{CT}$, the clinical presentation of the first is milder with patients fully conscious or slightly disoriented. The rupture of a vein in the prepontine or interpeduncular cisterns seems to be the bleeding source of non-aneurismal PMH [35].

In patients with a benign clinical presentation and a $\mathrm{PMH}$, the probability of finding a ruptured aneurysm varies between 2.5 and $8.9 \%$ [19,23,27,36,37]. Given this probability versus the clinical risks of DSA, adding DSA to a high quality CTA to exclude a ruptured aneurysm is increasingly debated [38].

\section{Purpose of the study}

This study aims to identify when a ruptured aneurysm can be excluded by CTA, thereby avoiding catheter angiography.

\section{Methods}

This is an observational retrospective study of all consecutive 241 adult patients who underwent both technically adequate catheter angiography and CTA for a suspicion of a ruptured aneurysm at a tertiary referral center, from January 1st 1998 to December 31st 2007. SAH was diagnosed by non-contrast CT or lumbar puncture. Arteriovenous malformations, tumors, cavernomas, infections, and trauma were excluded. Based on the final diagnosis established by conventional angiography or peroperatively, 166 patients had a bleeding aneurysm. The study, having been conducted according to the Institutional Ethical Committee's recommendations, was therefore deemed exempt of requiring its explicit approval.

\section{Imaging protocols}

The CTA exams were performed based on a customized protocol for each CT (General Electric Healthcare, Milwaukee, Wisconsin). Table 1 shows the dates of the different CT upgrades. A timed test injection was used to determine the optimal timing of the CTA data acquisition. It consisted of a single 5 to $10 \mathrm{~mm}$-thick slice (80 $\mathrm{kVp} / 100 \mathrm{~mA}$ ) positioned at the top of the frontal sinuses, acquired in a cine mode at a rate of one image every $2 \mathrm{~s}$ during intravenous administration of $20 \mathrm{~mL}$ of iodinated contrast material $(2.36 \mathrm{~mol} / \mathrm{L}\{300 \mathrm{mg} / \mathrm{mL}\}$ iodine) followed by $40 \mathrm{~mL}$ of water. The injection rate was 4-5 mL/s into an antecubital vein by means of a power injector, with a $10 \mathrm{~s}$ delay between the injection and the onset of data acquisition.

The CTA data acquisition was performed in a spiral mode according to the typical parameters defined in table 2. A caudocranial scanning direction was selected, covering the volume extending from the plane situated $10 \mathrm{~mm}$ below the foramen magnum to the roof of the lateral ventricles. The injected volume was $50 \mathrm{~mL}$ with an injection rate of $4-5 \mathrm{~mL} / \mathrm{s}$ followed by $40 \mathrm{~mL}$ of water.

Every patient underwent four-vessel DSA via a transfemoral intra-arterial approach with multiple projections. 3DRA was done whenever deemed necessary, mainly to improve aneurysm preoperative planning [6].

\section{Review process}

The review of the CTA and the initial reading were performed on a workstation (Advantage Windows, General Electric Healthcare, Milwaukee, Wisconsin) to allow interactive reconstruction and interpretation, which has proved to be more accurate than an isolated review of hard-copy images [39]. Axial raw images, multiplanar $2 \mathrm{D}$ reconstructions, maximum intensity projection reconstructions, and shaded surface display reconstructions with volume rendering technique were used for CTA review. Then, two experienced neuroradiologists blinded to the $\mathrm{CT}$ report and the DSA findings,

Table 1 Specifications of CT scanners from 1998 to 2007

\begin{tabular}{lll}
\hline Period & CT scanner specifications & Number of cases per scanner \\
\hline 1998 - November 1999 & GE Highspeed Advantage CT/i 1 detector row & 39 \\
\hline December 1999 - April 2002 & GE Lightspeed QX/i 4 detector rows & 60 \\
\hline May 2002 - November 2002 & GE Lightspeed ultra 8 detector rows & 12 \\
\hline December 2002 - November 2005 & GE Lightspeed 16 advantage 16 detector rows & 93 \\
\hline
\end{tabular}


Table 2 Typical acquisition parameters of the CT scanners

\begin{tabular}{|c|c|c|c|c|c|c|}
\hline Detector rows & Rotation speed (s) & Pitch & Detector collimation ( $\mathrm{mm}$ ) & Reconstruction interval (mm) & $\mathrm{KVp}$ & $\mathrm{mA}$ \\
\hline 1 & 1.0 & 1.5 & 1.0 & 0.5 & 120 & $240-280$ \\
\hline 4 & 0.8 & 0.75 & 1.25 & 0.8 & 120 & $240-280$ \\
\hline 8 & 0.8 & 0.675 & 1.25 & 0.75 & 120 & $240-280$ \\
\hline 16 & 0.5 & 1.375 & 0.625 & 0.5 & 120 & $240-280$ \\
\hline 64 & 0.6 & 0.516 & 0.625 & 0.5 & 100 & $300-320$ \\
\hline
\end{tabular}

independently examined the CTA of the false negative and positive cases.

Subsequently, the bleeding patterns of all CTA negative patients (true and false negatives) were classified as: perimesencephalic, aneurismal, or no visible SAH (xanthochromic lumbar puncture). This classification was based on the admission CT and the PMH definition from this article's introduction. The time between symptom onset and CT was calculated for the categories of $\mathrm{PMH}$ and no visible SAH.

\section{Data analysis}

A resident supervised by neuroradiologists read the CTA first and wrote the radiological report. With respect to the catheter angiography result, as the gold standard, each case was classified with respect to the presence of an aneurysm as true positive, true negative, false positive, or false negative. The sensitivity and specificity, as well as the positive and negative predictive values regarding the detection of intracranial aneurysms, were calculated based on the values in table 3 . The sensitivity was calculated with the formula True Positives/ (True Positives + False Negatives), i.e. 160/(160+6) before review, 164/(164+2) after. The specificity was calculated with the formula True Negatives/(True Negatives + False Positives), i.e. $72 /(72+3)$ before review, $75 /$ $(75+0)$ for the first reviewer and $74 /(74+1)$ for the second.

\section{Results}

The study sample consisted of 241 patients (105 male and 136 female) with SAH aged 20 to 86 years (mean 50.3, SD 14.2). Catheter angiographies were performed on average one day after the CTA (max. 13 days). Table 3 displays the numbers and percentages of true

Table 3 Results of CT angiography (CTA) vs. conventional angiography regarding the presence of an aneurysm

\begin{tabular}{lccc} 
& & \multicolumn{2}{c}{ Catheter Angiography } \\
\cline { 2 - 3 } CTA & Aneurysm + (\%) & Aneurysm + & No Aneurysm - \\
\hline & True Positives & False Positives \\
\cline { 2 - 4 } & No Aneurysm -(\%) & $6(2.5)$ & $72(30.0)$ \\
& False Negatives & True Negatives \\
\hline
\end{tabular}

positive, true negative, false positive and false negative cases with respect to the presence of an aneurysm. Table 4 shows the negative CTA cases correlated with their respective hemorrhage pattern.

\section{Clinical presentations of the negative CTA cases}

All of the patients with a perimesencephalic hemorrhage pattern presented in excellent clinical grade with a Glasgow Coma Scale (GCS) score of 15 and thus with a World Federation of Neurosurgeons (WFNS) classification score of 1 . Their average hospital stay was $5 \pm 3$ days. Out of the 16 cases with a no-hemorrhage pattern, 13 had a GCS score of 15 and a WFNS score of 1 , two had GCS scores of 13-14 and WFNS scores of 3-2 respectively. This data was unavailable for the last. The average hospital stay of patients with a no-hemorrhage pattern was $4 \pm 3$ days. Forty-one of the 43 patients with an aneurismal pattern had GCS scores of 12-15 and WFNS scores of 1-4. One patient had a GCS score of 3 and a WFNS score of 5 . This data was unavailable for the last. The average hospital stay of patients with an aneurismal pattern was $14 \pm 6$ days.

There were 6 cases in which an aneurysm was missed in their original CTA readings, but each one had an aneurismal hemorrhage pattern. All 35 patients with either a PMH or no-hemorrhage pattern on the initial $\mathrm{CT}$ had negative findings on DSA, confirming the negative CTAs. Therefore, this sample showed a $100 \%$ negative predictive value of CTA. Thirty-three (94\%) of these 35 patients had follow-up imaging. Thirty-one underwent repeat delayed DSA and two Magnetic Resonance Angiography. The last two patient's detailed neurological exams were asymptomatic at four months for one and six for the other, after the SAH.

When the blinded neuroradiologists reread the original CTAs of the false positive and false negative cases at a later date, each identified $4 / 6$ previously missed aneurysms. The first neuroradiologist corrected all false positive cases and the second 2/3. Before review, the sensitivity and specificity were $96.4 \%$ and $96.0 \%$ respectively. Both reviewers demonstrated a $98.8 \%$ sensitivity. The first had a $100 \%$ specificity and the second $98.7 \%$.

In this study, for the PMH patterns, the time from symptom onset to CT/CTA was between 1.3 hours and 7 days (median 19.5 hours, 3/19 cases over 48 hours) and between 2 hours and 12 days (median 25.5 
Table 4 Negative CT angiography (CTA) cases

\begin{tabular}{cccc}
\hline $\begin{array}{c}\text { Initial CT Hemorrhage Pattern of } \\
\text { Negative CTA Cases }\end{array}$ & $\begin{array}{c}\text { Aneurysm Found on Catheter } \\
\text { Angiography (CTA False Negatives) }\end{array}$ & $\begin{array}{c}\text { No Aneurysm Found on Catheter } \\
\text { Angiography (CTA True Negatives) }\end{array}$ & $\begin{array}{c}\text { Negative } \\
\text { Predictive } \\
\text { Value }\end{array}$ \\
\hline Aneurismal & 6 & 37 & $84.1 \%$ \\
\hline Perimesencephalic & 0 & 19 & $100 \%$ \\
\hline No hemorrhage & 0 & 16 & $100 \%$ \\
\hline
\end{tabular}

Distribution based on the initial $\mathrm{CT}$ and negative predictive values of the different hemorrhage groups.

hours, 7/16 cases over 48 hours) when no hemorrhage was seen.

\section{False negatives and false positives}

Out of 6 false negatives, one aneurysm was missed by all neuroradiologists on the CTA (16-slices). It was on the posterior communicating artery, adjacent to the skull bone. This aneurysm was thus misinterpreted as being part of the sphenoid bone due to the similar density of the injected contrast agent and bone (see figure 1). DSA combined with 3DRA is an imperfect gold standard as illustrated by another case [40]. The aneurysm was found only by the third catheter angiogram, 18 days after the bleeding, whereas a reviewer recognized it on the CTA. It was partially thrombosed and located on the middle cerebral artery. Only one of the reviewers

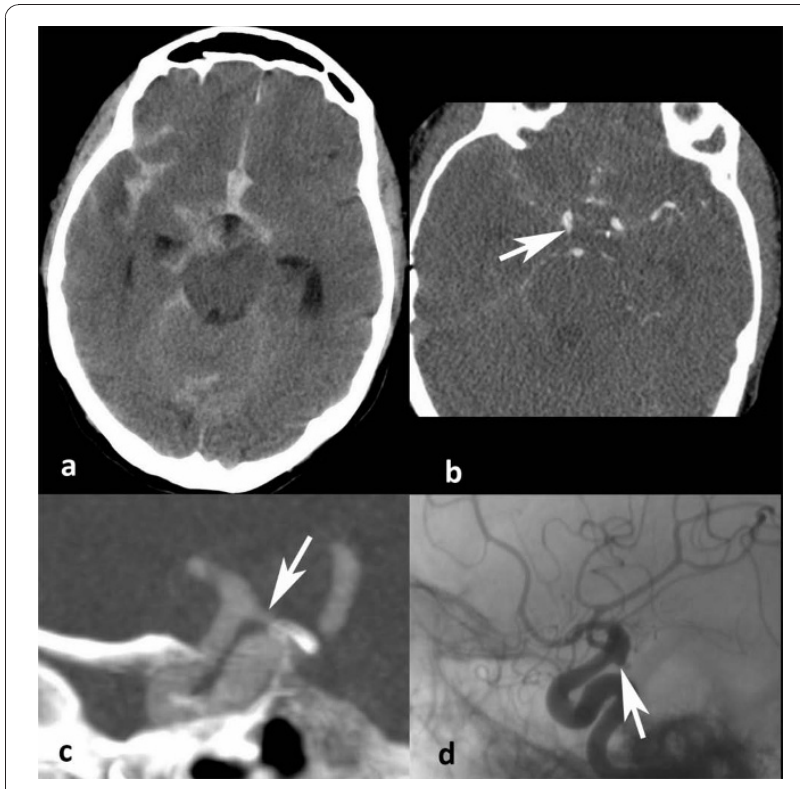

Figure 1 Missed aneurysm. Aneurysm missed by each neuroradiologist on the $C T$ Angiography (CTA). a Non-contrast $C T$ displaying the aneurismal SAH pattern. $\mathbf{b}$ CTA showing the posterior communicating aneurysm (arrow). c 3D reconstruction of the CTA showing the aneurysm filled with contrast material, appearing to be continuous with the sphenoid bone (arrow). d Angiogram of the same $3 \mathrm{~mm}$ aneurysm on the posterior communicating artery (arrow). missed a third aneurysm, found on the left middle cerebral artery (16-slices). The last three false negatives were not identified on the initial CTA reading, but detected later by both reviewers. They were found on: the left anterior cerebral artery (16-slice CT), the right anterior inferior cerebellar artery (16-slice CT) and the left internal carotid artery (64-slice CT).

The false positives had either no hemorrhage visible on the initial CT $(2 / 3)$ or an aneurismal hemorrhage pattern.

\section{Discussion}

Thirty-one percent of the patients in this study sample did not have a ruptured aneurysm (19\% had an aneurismal pattern, $8 \%$ had a $\mathrm{PMH}$ pattern, and $7 \%$ had nohemorrhage). This distribution into different SAH categories is comparable to that of Little et al 2007. That sample consisted of $23 \%$ without a ruptured aneurysm on the initial catheter angiography (16\% had an aneurismal pattern, $4 \%$ had a PMH pattern, and $3 \%$ had nohemorrhage) [40].

The present study's sensitivity and specificity are similar to others. A blinded review of false negative and positive cases corrected at least two thirds of them, thus showing its importance. A second reading proved useful in cases with an aneurismal hemorrhage pattern since errors happened only then.

The negative predictive value of CTA varied depending on whether the non-contrast CT showed an aneurismal hemorrhage pattern, a $\mathrm{PMH}$ pattern or a nohemorrhage pattern. When the non-contrast CT displayed a PMH or no-hemorrhage pattern, the CTA negative predictive value and sensitivity were both $100 \%$ with respect to 3DRA. This implied that in these cases, CTA was as good as 3DRA to exclude an aneurysm. Hence, CTA could have been used as the sole diagnostic imaging technique with its lower risks and costs and with greater facility of access (while the patient was still in the CT scanner).

First of all, Agid et al [41] retrospectively evaluated 193 CTAs with negative findings performed for SAH. Of these patients, 68 had a diffuse aneurismal or peripheral sulcal pattern, 93 had $\mathrm{PMH}$ and 32 had no blood on CT. All patients with PMH and with no blood on 
CT did not have an aneurysm detected by DSA. They concluded that in patients with $\mathrm{SAH}$, negative CTA findings are reliable in ruling out aneurysms in the PMH pattern or no blood on CT. DSA is indicated in the diffuse aneurismal pattern of $\mathrm{SAH}$, and repeat delayed DSA is required if the initial DSA findings are negative.

Secondly, Kershenovich et al [42] deduced from a retrospective study of 30 patients with negative CTAs, DSAs and PMH that brain CTA alone is a good and conclusive diagnostic tool to rule out aneurysms in patients presenting with the classic PMH pattern and could thus replace DSA. They also mention 8 patients diagnosed with SAH only by LP, where an initially negative CTA scan would have been sufficient to rule out an aneurysm.

Thirdly, in a series of 60 patients with SAH and negative CTA results, Westerlaan et al [10] reported 17 with a nonperimesencephalic (aneurismal) blood distribution, 30 with $\mathrm{PMH}$, and 13 without blood on CT. DSA was performed in $74 \%$ of the patients with $\mathrm{PMH}$ and without blood on the initial CT. All were true negatives. In the aneurismal blood distribution group, an aneurysm was found in 5 (29\%) patients, including 1 aneurysm seen only on DSA.

Ruigrok et al's [38] sensitivity analysis to evaluate the effect of different strategies following a PMH pattern shows that CTA only is the best diagnostic strategy. A fifth study reported a sensitivity, specificity, and negative predictive value of $100 \%$ for 15 patients with a $\mathrm{PMH}$ pattern [23]. It concluded that CTA was an adequate screening examination for vertebrobasilar aneurysms.

Pooling the results of these five studies with ours adds up to 187 patients with $\mathrm{PMH}$ and 69 patients with nohemorrhage on CT in five different countries. These demonstrate with greater confidence the reliability of CTA as the sole imaging diagnostic tool in the context of a PMH or no blood on CT.

Furthermore, this study verifies the dependability of CTA in patients with PMH or no blood on CT, even in the face of the latest gold standard, 3DRA and follow-up imaging ( $94 \%$ of our cases). Besides, it adds more patients in a real life clinical setting, for a condition with a low incidence.

The variability in time between symptom onset and CT (1.3 hours to 12 days) may have changed the category of certain cases from an aneurismal hemorrhage pattern to no visible hemorrhage, due to blood resorption with time. This did not affect the present study's results. Though, applying its conclusions in other settings, an aneurysm could be missed in patients with originally an aneurismal hemorrhage pattern who do not undergo catheter angiography. Therefore, repetition of this research in several institutions is required to explore this point.

Successive generations of CT with an increased number of detectors have provided clearer images for improved diagnostic comfort according to professional experience. Otherwise, no objective improvement in accuracy was observed with the evolution of scanners, as false negatives were scattered throughout the years and models. All the false positives and more false negatives were found when the 16-slice scanner was used, for a standardized number of cases. The most likely explanation appears to be the difference in pitch (table 2) or the contribution of chance as the number of misses is small and $38.7 \%$ of all cases were done on this machine.

\section{Conclusions}

This study shows that CT angiography is sufficient to exclude ruptured aneurysms without catheter angiography for patients with a PMH pattern or without any hemorrhage on the $\mathrm{CT}$, when done within a week of symptom onset. For all other SAH cases, if the CT angiogram is negative, catheter angiography is still required.

\section{Author details}

${ }^{1}$ Department of Radiology, Centre Hospitalier Universitaire Vaudois and University of Lausanne, 1011 Lausanne, Switzerland. ${ }^{2}$ Department of Neurosurgery, Centre Hospitalier Universitaire Vaudois and University of Lausanne, 1011 Lausanne, Switzerland. ${ }^{3}$ Department of Neurosurgery, Rudolf Magnus Institute of Neuroscience, University Medical Center Utrecht, Netherlands.

\section{Authors' contributions}

MK acquired the data, analyzed and interpreted the data, performed statistical analysis and drafted the manuscript. PM reviewed the CT angiograms, classified the subarachnoid hemorrhages and made critical revision of the manuscript for important intellectual content. SB reviewed the $C T$ angiograms and made critical revision of the manuscript for important intellectual content. ML made critical revision of the manuscript for important intellectual content. LR acquired the data and made critical revision of the manuscript for important intellectual content. RM conceived and designed the research, acquired the data, analyzed and interpreted the data, drafted the manuscript, handled supervision, made critical revision of the manuscript for important intellectual content. All authors read and approved the final manuscript.

\section{Competing interests}

The authors declare that they have no competing interests.

Received: 9 August 2010 Accepted: 21 January 2011 Published: 21 January 2011

\section{References}

1. van Gijn J, Kerr RS, Rinkel GJ: Subarachnoid haemorrhage. Lancet 2007, 369:306-318.

2. van der Wee N, Rinkel GJ, Hasan D, van Gijn J: Detection of subarachnoid haemorrhage on early CT: Is lumbar puncture still needed after a negative scan? J Neurol Neurosurg Psychiatry 1995, 58:357-359.

3. van Rooij WJ, Peluso JP, Sluzewski M, Beute GN: Additional value of 3D rotational angiography in angiographically negative aneurismal 
subarachnoid hemorrhage: how negative is negative? AJNR Am $J$ Neuroradiol 2008, 29:962-966.

4. van Rooij WJ, Sprengers ME, de Gast AN, Peluso JP, Sluzewski M: 3D rotational angiography: the new gold standard in the detection of additional intracranial aneurysms. AJNR Am J Neuroradiol 2008, 29:976-979.

5. Hirai T, Korogi Y, Suginohara K, Ono K, Nishi T, Uemura S, Yamura M, Yamashita Y: Clinical usefulness of unsubtracted 3D digital angiography compared with rotational digital angiography in the pretreatment evaluation of intracranial aneurysms. AJNR Am J Neuroradiol 2003, 24:1067-1074.

6. Hochmuth A, Spetzger U, Schumacher M: Comparison of threedimensional rotational angiography with digital subtraction angiography in the assessment of ruptured cerebral aneurysms. AJNR Am J Neuroradiol 2002, 23:1199-1205.

7. Chappell ET, Moure FC, Good MC: Comparison of computed tomographic angiography with digital subtraction angiography in the diagnosis of cerebral aneurysms: a meta-analysis. Neurosurgery 2003, 52:624-631.

8. Wintermark M, Uske A, Chalaron M, Regli L, Maeder P, Meuli R, Schnyder P, Binaghi S: Multislice computerized tomography angiography in the evaluation of intracranial aneurysms: a comparison with intraarterial digital subtraction angiography. J Neurosurg 2003, 98:828-836.

9. Villablanca JP, Hooshi P, Martin N, Jahan R, Duckwiler G, Lim S, Frazee J, Gobin YP, Sayre J, Bentson J, Viñuela F: Three-dimensional helical computerized tomography angiography in the diagnosis, characterization and management of middle cerebral artery aneurysms: comparison with conventional angiography and intraoperative findings. J Neurosurg 2002, 97:1322-1332.

10. Westerlaan HE, Gravendeel J, Fiore D, Metzemaekers JD, Groen RJ, Mooij JJ, Oudkerk M: Multislice CT angiography in the selection of patients with ruptured intracranial aneurysms suitable for clipping or coiling. Neuroradiology 2007, 49:997-1007.

11. Lubicz B, Levivier M, François O, François O, Thoma P, Sadeghi N, Collignon L, Balériaux D: Sixty-four-row multisection $\mathrm{CT}$ angiography for detection and evaluation of ruptured intracranial aneurysms: interobserver and intertechnique reproducibility. AJNR Am J Neuroradiol 2007, 28:1949-1955.

12. Agid R, Lee SK, Willinsky RA, Farb RI, terBrugge KG: Acute subarachnoid hemorrhage: using 64-slice multidetector CT angiography to "triage" patients' treatment. Neuroradiology 2006, 48:787-794.

13. Ringer AJ, Rodriguez-Mercado R, Veznedaroglu E, Levy El, Hanel RA, Mericle RA, Lopes DK, Lanzino G, Boulos AS: Defining the risk of retreatment for aneurysm recurrence or residual after initial treatment by endovascular coiling: a multicenter study. Neurosurgery 2009, 65:311-315.

14. Fifi JT, Meyers PM, Lavine SD, Cox V, Silverberg L, Mangla S, Pile-Spellman J: Complications of modern diagnostic cerebral angiography in an academic medical center. I Vasc Interv Radiol 2009, 20:442-447.

15. Kassell NF, Torner JC, Haley EC Jr, Jane JA, Adams HP, Kongable GL: The International Cooperative Study on the timing of aneurysm surgery, I: Overall management results. J Neurosurg 1990, 73:18.

16. Sames TA, Storrow AB, Finkelstein JA, Magoon MR: Sensitivity of newgeneration computed tomography in subarachnoid hemorrhage. Acad Emerg Med 1996, 3:16.

17. Sidman $R$, Connolly E, Lemke T: Subarachnoid hemorrhage diagnosis: lumbar puncture is still needed when the computed tomography scan is normal. Acad Emerg Med 1996, 3:827.

18. Boesiger BM, Shiber JR: Subarachnoid hemorrhage diagnosis by computed tomography and lumbar puncture: are fifth generation CT scanners better at identifying subarachnoid hemorrhage? J Emerg Med 2005, 29:23-27.

19. Rinkel GJ, Wijdicks EF, Vermeulen M, Ramos LM, Tanghe HL, Hasan D, Meiners LC, van Gijn J: Nonaneurysmal perimesencephalic subarachnoid hemorrhage: $\mathrm{CT}$ and MR patterns that differ from aneurysm rupture. AJNR Am J Neuroradiol 1991, 12:829-834.

20. Rinkel GJ, Wijdicks EF, Vermeulen M, Hasan D, Brouwers PJ, van Giin J: The clinical course of perimesencephalic nonaneurysmal subarachnoid hemorrhage. Ann Neurol 1991, 29:463-468.

21. Rinkel GJ, Wijdicks EF, Hasan D, Kienstra GE, Franke CL, Hageman LM, Vermeulen M, van Gijn J: Outcome in patients with subarachnoid haemorrhage and negative angiography according to pattern of haemorrhage on computed tomography. Lancet 1991, 338:964-968.
22. Brilstra EH, Hop JW, Rinkel GJ: Quality of life after perimesencephalic haemorrhage. J Neurol Neurosurg Psychiatry 1997, 63:382-384.

23. Velthuis BK, Rinkel GJ, Ramos LM, Witkamp TD, van Leeuwen MS: Perimesencephalic hemorrhage. Exclusion of vertebrobasilar aneurysms with CT angiography. Stroke 1999, 30:1780-1786.

24. Ildan F, Tuna M, Erman T, Gocer Al, Cetinalp E: Prognosis and prognostic factors in nonaneurysmal perimesencephalic hemorrhage: A follow-up study in 29 patients. Surg Neurol 2002, 57:160-166.

25. Goergen SK, Barrie D, Sacharias N, Waugh JR: Perimesencephalic subarachnoid haemorrhage: negative angiography and favourable prognosis. Australas Radiol 1993, 37:156-160.

26. Kitahara T, Ohwada T, Tokiwa K, Kurata A, Miyasaka Y, Yada K, Kan S: Clinical study in patients with perimesencephalic subarachnoid hemorrhage of unknown etiology. No Shinkei Geka 1993, 21:903-908.

27. Pinto AN, Ferro JM, Canhao P, Campos J: How often is a perimesencephalic subarachnoid haemorrhage $\mathrm{CT}$ pattern caused by ruptured aneurysms? Acta Neurochir (Wien) 1993, 124:79-81.

28. Ausman Jl: Perimesencephalic nonaneurysmal subarachnoid hemorrhage: what is it? what are we missing? Surg Neurol 2002, 57:211.

29. Schwartz TH, Solomon RA: Perimesencephalic nonaneurysmal subarachnoid hemorrhage: review of the literature. Neurosurgery 1996, 39:433-440.

30. Zentner J, Solymosi L, Lorenz M: Subarachnoid hemorrhage of unknown etiology. Neurol Res 1996, 18:220-226

31. Schievink WI, Wijdicks EF: Pretruncal subarachnoid hemorrhage: an anatomically correct description of the perimesencephalic subarachnoid hemorrhage. Stroke 1997, 28:2572.

32. van Gijn J, van Dongen KJ, Vermeulen M, Hijdra A: Perimesencephalic hemorrhage: a nonaneurysmal and benign form of subarachnoid hemorrhage. Neurology 1985, 35:493-497.

33. Schwartz TH, Farkas J: Quadrigeminal non-aneurysmal subarachnoid hemorrhage: a true variant of perimesencephalic subarachnoid hemorrhage: case report. Clin Neurol Neurosurg 2003, 105:95-98.

34. Schwartz TH, Mayer SA: Quadrigeminal variant of perimesencephalic nonaneurysmal subarachnoid hemorrhage. Neurosurgery 2000, 46:584-588.

35. van der Schaaf I, Velthuis BK, Gouw A, Rinkel GJ: Venous drainage in perimesencephalic hemorrhage. Stroke 2004, 35:1614-1618.

36. van Calenbergh F, Plets C, Goffin J, Velghe L: Nonaneurysmal subarachnoid hemorrhage: prevalence of perimesencephalic hemorrhage in a consecutive series. Surg Neurol 1993, 39:320-323.

37. Alén JF, Lagares A, Lobato RD, Gómez PA, Rivas JJ, Ramos A: Comparison between perimesencephalic nonaneurysmal subarachnoid hemorrhage and subarachnoid hemorrhage caused by posterior circulation aneurysms. J Neurosurg 2003, 98:529-535.

38. Ruigrok YM, Rinkel GJ, Buskens E, Velthuis BK, van Gijn J: Perimesencephalic hemorrhage and $\mathrm{CT}$ angiography: a decision analysis. Stroke 2000, 31:2976-2983.

39. Young N, Dorsch NW, Kingston RJ, Soo MY, Robinson A: Spiral CT scanning in the detection and evaluation of aneurysms of the Circle of Willis. Surg Neurol 1998, 50:50-61.

40. Little AS, Garrett M, Germain R, Farhataziz N, Albuquerque FC, McDougall CG, Zabramski JM, Nakaji P, Spetzler RF: Evaluation of patients with spontaneous subarachnoid hemorrhage and negative angiography. Neurosurgery 2007, 61:1139-1150.

41. Agid R, Andersson T, Almqvist H, Willinsky RA, Lee SK, terBrugge KG, Farb RI, Söderman M: Negative CT angiography findings in patients with spontaneous subarachnoid hemorrhage: when is digital subtraction angiography still needed? AJNR Am J Neuroradiol 2010, 31:696-705.

42. Kershenovich A, Rappaport ZH, Maimon S: Brain computed tomography angiographic scans as the sole diagnostic examination for excluding aneurysms in patients with perimesencephalic subarachnoid hemorrhage. Neurosurgery 2006, 59:798-802.

\section{Pre-publication history}

The pre-publication history for this paper can be accessed here: http://www.biomedcentral.com/1471-2377/11/8/prepub

doi:10.1186/1471-2377-11-8

Cite this article as: Kelliny et al:: Cerebral aneurysm exclusion by $\mathrm{CT}$ angiography based on subarachnoid hemorrhage pattern: a retrospective study. BMC Neurology 2011 11:8. 